\title{
A MONTHLY CIRCULATION CLIMATOLOGY FOR SWEDEN AND ITS APPLICATION TO A WINTER TEMPERATURE CASE STUDY
}

\author{
DELIANG CHEN* \\ Department of Earth Sciences, Göteborg University, 40530 Göteborg, Sweden
}

\begin{abstract}
Atmospheric circulation is important in determining the surface climate and environment. To quantify its effect, circulation indices or classifications of circulation type are often used. In this study, the classification system developed by Lamb (1950. Quarterly Journal of the Royal Meteorological Society 76: 393-438) is applied to obtain circulation information for Sweden on a monthly basis. For that purpose, monthly mean sea-level pressure (MSLP) data from 1873 to 1995 is used to derive six circulation indices and to provide a circulation catalogue with 27 circulation types. The frequency of circulation types over different periods is computed and described. Four major types (cyclonic, C; west, W; southwest, SW; anticyclonic, A) have been identified. The catalogue and the associated indices provide a tool for interpreting the regional climate and for developing statistical downscaling models to derive regional climate change scenarios for Sweden.

An example is given to illustrate the application and usefulness of this climatology. It deals with the linkage between the mean regional temperature in southwestern Sweden and the large-scale circulation. It is shown that directional flows with a westerly component clearly favour a positive temperature anomaly, while the anticyclonic condition often induces a negative anomaly. Moreover, it is the westerly or southwesterly flows that accompany extreme positive temperature anomalies, whereas anticyclonic conditions play an important role in creating extreme negative temperature anomalies. Further, the derived indices have a relationship with temperature anomalies, established via a statistical model. Stepwise multiple regression was used, leading to a successful model with only three indices. Using the model, $70 \%$ of the total variance in the temperature anomalies between 1887 and 1994 has been reconstructed from the pressure, which leads to the conclusion that the circulation is a critical determinant of the January temperature and that the derived climatology is useful in explaining the temperature anomalies. Copyright (C) 2000 Royal Meteorological Society.
\end{abstract}

KEY WORDS: Sweden; circulation; Lamb's weather type; statistical downscaling; winter temperature

\section{INTRODUCTION}

Local and regional climate are influenced by both large-scale atmospheric circulation and surface features (e.g. Kidson, 1994). As spatial distribution of surface characteristics is relatively stable, it would be expected that large-scale climate plays an important role in causing changes in local climate. Studies of local climate change are often linked to variations in the atmospheric circulation (e.g. Yarnal, 1984).

In characterizing large-scale circulation, an index which describe features of the large-scale circulation can be useful in explaining changes in surface climate (e.g. Kozuchowski, 1993). One such index is the 'zonal index', originally developed by Rossby (1941) which has been widely used in studying European climate (Kozuchowski et al., 1992). Due to the improved understanding of the teleconnection patterns of the planetary atmosphere (e.g. Wallace and Gutzler, 1981), more useful indices have been developed and used in regional climate research worldwide (e.g. Malmgren et al., 1998). As an example, the regional temperature variability in Sweden has been successfully associated with the North Atlantic Oscillation (NAO) by Chen and Hellström (1999).

Another description of circulation is based on weather types (e.g. Barry et al., 1981). In Europe, the concept of 'Grosswetterlage' has found many applications (e.g. Schubert, 1994). This approach builds on

\footnotetext{
* Correspondence to: Department of Earth Sciences, Göteborg University, Box 460, 40530 Göteborg, Sweden; e-mail: deliang@gvc.gu.se; http://www.gvc.gu.se/ngeo/deliang/deliang.htm
}

Copyright (C) 2000 Royal Meteorological Society 
a classification scheme to group a large number of meteorological data into distinctive types of weather (Barry, 1980). The schemes are usually classified as either objective or subjective. Several objective schemes exist; the majority of them based on multivariate techniques that can be easily performed by computer (Davis and Kalkstein, 1990). Objective schemes have the advantage of being effective and repeatable. For example, if an empirical orthogonal function (EOF) analysis is used, only a few weather types are usually needed to classify a great portion of the samples. However, mathematical constraints may limit the applicability of such techniques to real situations. Another problem is that the types defined depend on the data used, which means that the classification may vary, if data from different periods are used. This is problematic if the focus is not on condensing the information, but rather on studying the long-term variations. Furthermore, as pointed out by Key and Crane (1995), some subjectivity is always present in any 'objective' scheme depending on the options employed.

On the other hand, subjective schemes are usually based on experience and distinctively defined patterns. This makes them straightforward and easy to interpret. The obvious drawback is the subjectivity and inefficiency of the judgement. However, this disadvantage can be overcome by defining objective rules for such a scheme, making automatic determinations possible (Jenkinson and Collison, 1977). A successful example is the computerized classification based on the Lamb (1950) scheme (e.g. Briffa, 1995). This method has been compared with an objective method (Jones et al., 1993). Since our aim is to obtain standardized circulation information that is independent of data examined, the automatic Lamb classification is a reasonable choice. This method is adopted here to create a circulation type catalogue for Sweden. The motivation of the work is based on the facts that the atmospheric circulation is an important factor in shaping the climate over Sweden (e.g. Chen and Hellström, 1999) and no such classification has been developed for this region to the author's knowledge. Thus, it is expected that the catalogue will constitute a useful tool in climate research in this region.

It should be noted that the Lamb (1950) scheme was originally developed to classify daily weather types (Jones and Kelly, 1982). Thus, its application to the monthly circulation needs to be tested and justified. A case study on winter temperature is thus given to show its usefulness for monthly climatology. In general, the types classified should be interpreted as monthly mean circulation patterns that are composed of averages of daily weather types. Since the method is based on a set of indices describing geostrophic wind and vorticity conditions, it also provides a useful by-product, namely circulation indices. The classification is useful not only reducing the dimensions of the original data, but also in providing a framework to study relationships between regional climate and circulation type. The latter is demonstrated with an example concerning the January temperatures in southwestern Sweden. In a recent study, Kilsby et al. (1998) have used the atmospheric circulation indices derived for the UK for predicting rainfall statistics in England and Wales. The circulation types and indices will be regarded as circulation climatology in this study.

The objectives of this study are: (i) to construct a circulation type catalogue for Sweden using the Lamb scheme; (ii) to examine changes in the occurrence frequency of a suite of major large-scale atmospheric circulation types; and (iii) to demonstrate the usefulness of the circulation climatology by studying the relationship between large-scale circulation and January temperatures.

In Section 2 the data used and method of classification are described. The classification results are presented in Section 3. Section 4 provides an example of temperature analysis based on the circulation climatology.

\section{DATA AND IMPLEMENTATION OF THE CLASSIFICATION SCHEME}

\subsection{Grid-point pressure data}

Large-scale circulation is represented by a dataset containing monthly mean sea-level pressure (MSLP) data on a $5^{\circ}$ latitude by $10^{\circ}$ longitude grid-point basis for the Northern Hemisphere. The sources of the original chart data are given in Jones (1987) and the digital data was obtained from the homepage of the 
Climate Research Unit (CRU) at http://www.cru.uea.ac.uk/cru/data/pressure.htm. A further description of the dataset can be found in Trenberth and Paolino (1980) and Basnett and Parker (1997).

In this study, the pressure data from 1987 to 1995 was extracted for an area bounded by $52.5^{\circ}$ and $72.5^{\circ} \mathrm{N}$, and $5^{\circ}$ and $27.5^{\circ} \mathrm{E}$, essentially centred in Sweden (Figure 1). Missing values are rare and only found for $p(1)$ and $p(14)$, and they are replaced by linearly interpolated values from the surrounding grids.

\subsection{The classification scheme}

The classification of circulation is based the manual scheme developed by Lamb (1950) for the British Isles. This scheme was automated by Jenkinson and Collison (1977) by defining a number of indices and classification rules. Following Briffa (1995), the Lamb classification is computerized by means of the following objective rules based on the geostrophic wind and vorticity over the whole area shown in Figure 1. The rules are based on the following six circulation indices:

$$
\begin{aligned}
u= & 0.5[p(12)+p(13)-p(4)-p(5)], \\
v= & 0.499[p(5)+2 p(9)+p(13)-p(4)+2 p(8)-p(12)], \\
V= & \sqrt{u^{2}+v^{2}} \\
\xi_{u}= & 0.529[p(15)+p(16)-p(8)-p(9)]-0.478[p(8)+p(9)-p(1)-p(2)], \\
\xi_{v}= & 0.499[p(6)+2 p(10)+p(14)-p(5)-2 p(9)-p(13)-p(4)-2 p(8)-p(12) \\
& +p(3)+2 p(7)+p(11)], \\
\xi= & \xi_{u}+\xi_{v},
\end{aligned}
$$

where $p(n)$ is the MSLP at grid point $n, u$ and $v$ are westerly (zonal) and southerly (meridional) components of the geostrophic wind, $V$ the combined wind speed, $\xi_{u}$ (meridional gradient of $u$ ) and $\xi_{v}$ (zonal gradient of $v$ ) westerly and southerly shear vorticity, and $\xi$ is the total shear vorticity. MSLP are used because it has the longest record of all circulation variables. All the indices have units of $\mathrm{hPa}$ per $10^{\circ}$ latitude at $60^{\circ} \mathrm{N}$. The various constants appeared in the equation are derived from the fact that the grid cells represent areas of different sizes. Once $u$ and $v$ are known, the wind direction can be determined. There are basically two main categories of circulation type. The so-called directional flow types (north, N; northeast, NE; east, E; southeast, SE; south, S; southwest, SW; west, W; northwest, NW) are characterized by coherent wind direction $(|\xi|<V)$. The other category emphasizes rotation of the atmosphere $(|\xi|>2 V)$, which can either be cyclonic (C) or anticyclonic (A). There is also a possibility of hybrid categories $(V<|\xi|<2 V)$, which can be any combination of the two main categories. In the case where

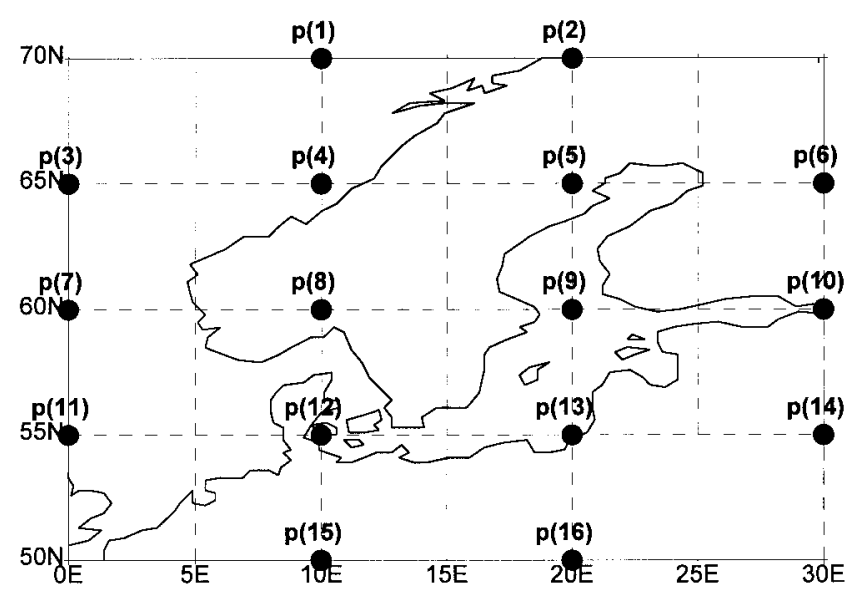

Figure 1. Map showing the grid points used in constructing the circulation climatology 
$V<6$ and $|\xi|<|6|$, the circulation is unclassified (UD). The classification rules are taken from Briffa (1995), since the latitude used by Briffa (1995) is close to that in this study. Altogether, 27 types are possible.

\subsection{The averaged temperature data}

The temperature data is an average over 30 stations in southwestern Sweden and five in northern Denmark derived by Moberg and Alexandersson (1997). All the stations are within a box from $55^{\circ}$ to $60^{\circ} \mathrm{N}$, and from $10^{\circ}$ to $15^{\circ} \mathrm{E}$. The data are given as anomalies with respect to $1961-1990$ mean for the period 1861-1994. The mean January temperature anomaly is used in this study and regarded as a mean for southwestern Sweden.

\section{RESULTS}

\subsection{Frequencies of circulation types}

The objective scheme described above was used to infer circulation types for every month from 1873 to 1995. A brief description of the main characteristics of the circulation types is given below.

To see how the scheme operates on the monthly data, an inspection is made of various types identified during different months and years, which shows that the classification performs well and that the situations in different months with same circulation type are reasonably similar.

The frequencies of the 27 circulation types over the period 1873-1995 are displayed in Figure 2. Two possible types missing, one is the anticyclonic combined with northeasterly flow (ANE) and the other unclassified (UD). The occurrence of the majority of the types is below $5 \%$, implying that a few types should be enough to describe the most frequent situations for Sweden. If $8.3 \%$ (corresponding to once a year on the average) is defined as the lower boundary of dominant types, only four types, i.e. A, C, W, and SW, can be considered as frequent. These four types account for $65.7 \%$ of all the months and thus can be taken as major types. It is noted all hybrid types are infrequent.

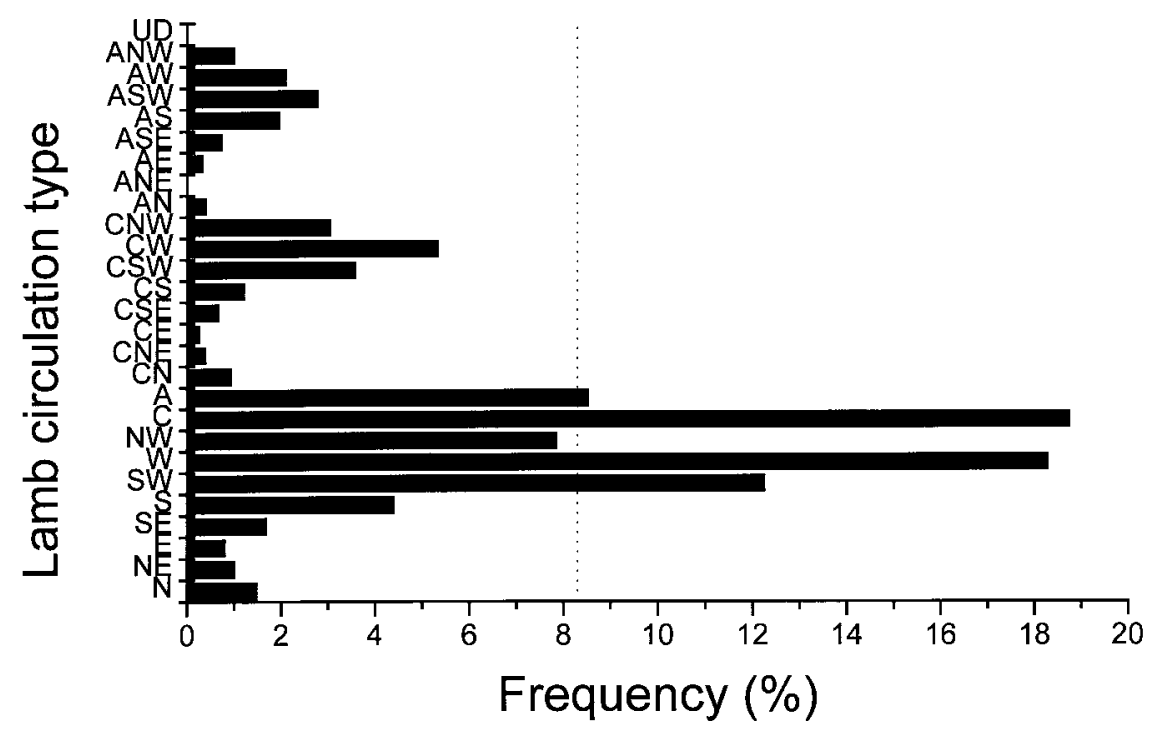

Figure 2. Frequency distribution of the Lamb circulation types during 1887 and 1995 


\subsection{Monthly frequencies of the circulation types}

It is interesting to examine seasonal variations in the frequency of the circulation types. Table I gives the frequencies for each month. The overall feature is that a shift between two modes, one with more frequent directional flows (Sep-Jan) and the other with more frequent rotational flows (Apr-Aug), dominates the seasonal variation. Between the two modes is a transitional period (Feb-Apr) which shows roughly equal importance of the two types of flows. The dominant directional flow is W and SW, while the rotational flows are dominated by $\mathrm{C}$. It is clear that $\mathrm{C}$ is the most frequent type in July, and $\mathrm{W}$ and SW occur frequently in January.

\subsection{Seasonal variation of frequencies of the major types}

To show the seasonal variations of the major circulation types more clearly, the frequencies of the four most frequent types are plotted as a function of month in Figure 3. The strongest seasonal variation is seen for type $\mathrm{C}$, though a clear variation can also be identified for other types apart from type NW. For most of the time, frequencies of $\mathrm{C}$ and $\mathrm{A}$ appear to be anticorrelated. Type A seems to have a similar seasonal variation as type SW with a 1 month time delay. There are fairly stable and low occurrences of type W (Apr-Aug). Westerlies are more common during Dec-Mar and Sep-Oct.

\subsection{Temporal variation of the frequencies for the major types}

In studying climate change over a region, the question is often raised as to the extent to which the changes identified are due to changes in the circulation or other factors such as the enhanced greenhouse effect. It is therefore of interest to study the temporal variation of the frequencies (Bardossy and Caspary,

Table I. Monthly frequencies (\%) of the circulation types between 1873 and $1995^{\mathrm{a}}$

\begin{tabular}{lcccccccccccc}
\hline Type & Jan & Feb & Mar & Apr & May & Jun & Jul & Aug & Sep & Oct & Nov & Dec \\
\hline N & 0 & 1.6 & 2.4 & 1.6 & 3.3 & 4.9 & 1.6 & 0.8 & 1.6 & 0 & 0 & 0 \\
NE & 0 & 1.6 & 0.8 & 0 & 5.7 & 3.3 & 0 & 0.8 & 0 & 0 & 0 & 0 \\
E & 0.8 & 0.8 & 0.8 & 1.6 & 3.3 & 0.8 & 0 & 0.8 & 0 & 0 & 0 & 0.8 \\
SE & 0.8 & 3.3 & 0.8 & 7.3 & 4.1 & 0 & 0 & 0 & 1.6 & 1.6 & 0.8 & 0 \\
S & 6.5 & 4.9 & 7.3 & 5.7 & 4.1 & 0 & 0 & 1.6 & 2.4 & 5.7 & 8.9 & 5.7 \\
SW & $\mathbf{1 8 . 7}$ & $\mathbf{1 1 . 4}$ & $\mathbf{1 1 . 4}$ & 8.1 & 5.7 & 0.8 & 7.3 & 7.3 & $\mathbf{1 6 . 3}$ & $\mathbf{1 9 . 5}$ & $\mathbf{2 0 . 3}$ & $\mathbf{2 0 . 3}$ \\
W & $\mathbf{2 5 . 2}$ & $\mathbf{1 7 . 9}$ & $\mathbf{2 0 . 3}$ & $\mathbf{1 0 . 6}$ & $\mathbf{1 1 . 4}$ & $\mathbf{1 2 . 2}$ & $\mathbf{1 3}$ & $\mathbf{1 3 . 8}$ & $\mathbf{2 9 . 3}$ & $\mathbf{2 6 . 8}$ & $\mathbf{1 5 . 4}$ & $\mathbf{2 3 . 6}$ \\
NW & 8.9 & 8.9 & 9.8 & 7.3 & 4.9 & $\mathbf{1 1 . 4}$ & $\mathbf{1 2 . 2}$ & 6.5 & 8.9 & 2.4 & 7.3 & 5.7 \\
C & 8.1 & 8.9 & $\mathbf{1 1 . 4}$ & $\mathbf{1 7 . 1}$ & $\mathbf{2 4 . 4}$ & $\mathbf{3 5 . 8}$ & $\mathbf{4 1 . 5}$ & $\mathbf{3 9 . 8}$ & 8.9 & 7.3 & $\mathbf{1 3 . 0}$ & 8.9 \\
A & 8.9 & $\mathbf{1 4 . 6}$ & $\mathbf{1 7 . 9}$ & $\mathbf{1 3 . 0}$ & 8.9 & 4.1 & 1.6 & 4.1 & 6.5 & $\mathbf{1 0 . 6}$ & 7.3 & 4.9 \\
CN & 0 & 0 & 1.6 & 0.8 & 3.3 & 3.3 & 1.6 & 0 & 0.8 & 0 & 0 & 0 \\
CNE & 0 & 0.8 & 0 & 0.8 & 1.6 & 0.8 & 0 & 0 & 0 & 0 & 0 & 0.8 \\
CE & 0 & 0 & 0 & 1.6 & 0 & 0.8 & 0 & 0 & 0 & 0.8 & 0 & 0 \\
CSE & 0 & 0.8 & 1.6 & 1.6 & 1.6 & 0 & 0 & 0.8 & 0.8 & 0.8 & 0 & 0 \\
CS & 0 & 1.6 & 1.6 & 1.6 & 0.8 & 2.4 & 0 & 0 & 0 & 0 & 1.6 & 4.9 \\
CSW & 3.3 & 2.4 & 2.4 & 2.4 & 1.6 & 0.8 & 4.1 & 5.7 & 4.1 & 6.5 & 4.9 & 4.9 \\
CW & 7.3 & 4.9 & 0 & 3.3 & 3.3 & 5.7 & 6.5 & 9.8 & 5.7 & 5.7 & 5.7 & 6.5 \\
CNW & 1.6 & 2.4 & 2.4 & 0 & 2.4 & 10.6 & 7.3 & 4.9 & 1.6 & 0.8 & 0.8 & 1.6 \\
AN & 0.8 & 0 & 0 & 0.8 & 0.8 & 0 & 1.6 & 0.8 & 0 & 0 & 0 & 0 \\
ANE & 0 & 0 & 0 & 0 & 0 & 0 & 0 & 0 & 0 & 0 & 0 & 0 \\
AE & 0 & 0 & 0 & 0.8 & 1.6 & 0.8 & 0 & 0 & 0.8 & 0 & 0 & 0 \\
ASK & 0.8 & 1.6 & 0 & 2.4 & 1.6 & 0 & 0 & 0.8 & 0.8 & 0 & 0 & 0.8 \\
AS & 3.3 & 4.9 & 3.3 & 2.4 & 1.6 & 0 & 0 & 1.6 & 0 & 2.4 & 1.6 & 2.4 \\
ASW & 3.3 & 2.4 & 2.4 & 2.4 & 0.8 & 0 & 0 & 0 & 4.9 & 5.7 & 6.5 & 4.9 \\
AW & 0.8 & 2.4 & 1.6 & 3.3 & 0.8 & 0.8 & 0 & 0 & 4.9 & 2.4 & 4.9 & 3.3 \\
ANW & 0.8 & 1.6 & 0 & 3.3 & 2.4 & 0.8 & 1.6 & 0 & 0 & 0.8 & 0.8 & 0 \\
UD & 0 & 0 & 0 & 0 & 0 & 0 & 0 & 0 & 0 & 0 & 0 & 0 \\
\hline a & & & & & & & & & & & & 0 \\
\end{tabular}

a Bold numbers indicate frequency over $10 \%$. 


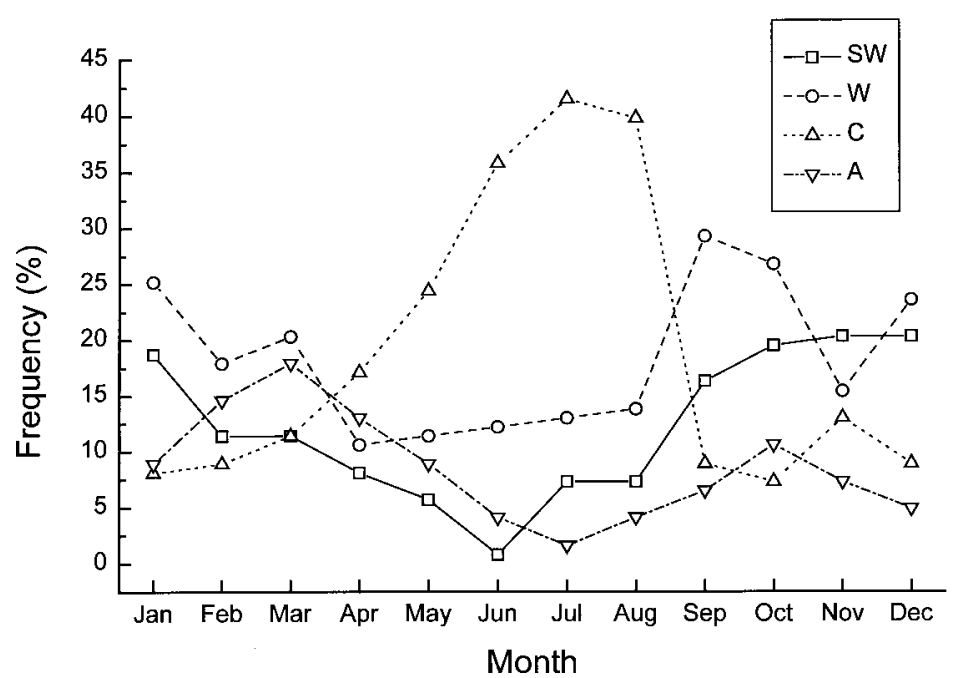

Figure 3. Seasonal variation of the frequency distribution for four major circulation types during 1873 and 1995

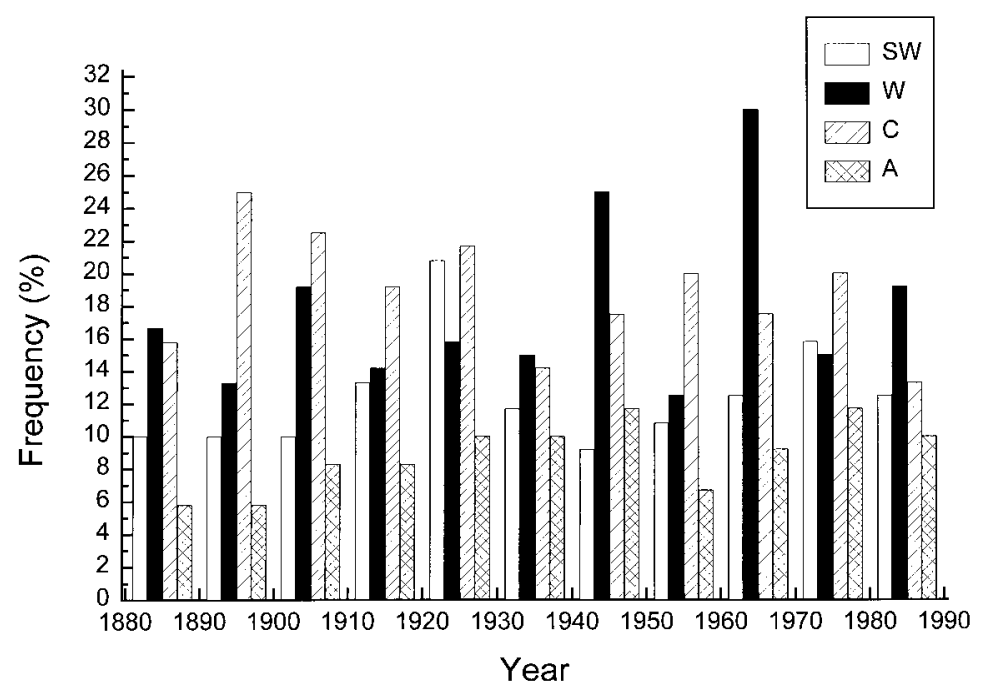

Figure 4. Frequency changes of five major circulation types during 1880 and 1990

1990). Figure 4 shows frequency changes over a 10-year interval from 1880 to 1990 for the five most frequent circulation types. Again, the temporal evolution is dominated by changes to the frequencies of $\mathrm{W}$ and $\mathrm{C}$. The changes in the frequencies of the two types are often negatively correlated, i.e. when the frequency of $\mathrm{C}$ decreases, the frequency of $\mathrm{W}$ increases. Variations in $\mathrm{W}$ are also relatively large.

\section{RELATIONSHIP BETWEEN THE JANUARY TEMPERATURE AND THE CIRCULATION}

The January temperature anomalies are related to the circulation types and the indices in order to establish relationships between the two. Figure 5 displays the temperature anomalies for January associated with the five most frequent circulation types. Figure 5(a) shows the estimated means and associated errors. Due to differing sample sizes for the five groups (10-31) and variability within each group, an estimate of the uncertainty in the estimated means is necessary. The error bars show calculated 


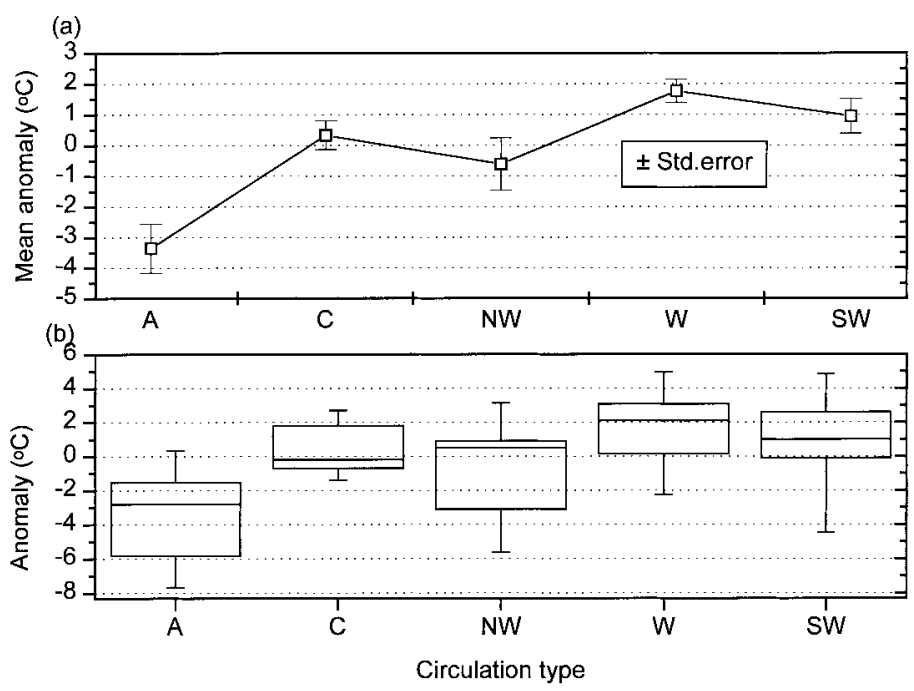

Figure 5. The temperature anomaly associated with the circulation types: (a) means with the standard error bars; (b) the Box-Wisker plot, the bottom of the vertical line marks the 5th percentile. The bottom of the box marks the 25 th percentile, the median line marks the 50th percentile, the top of the box marks the 75th percentile, and the top of the vertical line marks the 95 th percentile

standard errors. From Figure 5(a), a significant difference between cyclonic and anticyclonic conditions is evident. While anticyclonic conditions mainly lead to negative anomalies with varying amplitude, positive and relatively stable anomalies are often the case under cyclonic conditions. For the three directional flows, the difference is not that large. However, it can still be recognized that the NW type generally favours a cooler climate, whereas SW and W are biased toward the positive temperature anomalies, although variation within each group is considerable. This is obvious in the Box-Wisker plot (Figure 5(b)), which shows that extreme temperatures can be associated with more than one circulation type due to pronounced variations for any one circulation type. Similar studies (e.g. Perry and Barry, 1973) have also recognized the 'within-type' difference problem. Nevertheless, it is clear that extremely high temperatures are linked with advection of SW or W flows with the opposite being associated with anticyclonic or NW flows.

It is expected that the circulation types can only explain part of the variance in the temperature, because of the limited number of the types and more or less arbitrary divisions between the groups. An alternative way to study the association between the circulation and the temperature is to apply the six circulation indices. This provides a new possibility of mathematical modelling thanks to the continuous nature of the derived indices. A statistical approach, which involves regression of the temperature anomalies to the indices, will be employed to study the effect of the relationship.

Since the derived indices are inter-correlated due to the atmospheric dynamics and the nature of the indices, part of the information contained by one index is also present in another. Thus, a stepwise multiple regression model is chosen to link the temperature anomalies (predictant) and the indices (predictors). The criteria used to include an index in the model is the $95 \%$ confidence level. If the index is not significant at the $95 \%$ level according to a $F$-test, it is excluded. Finally, three indices are selected and the model takes the form as follows:

$$
T_{\mathrm{a}}=-3.48+0.079 v+0.32 V+0.17 \xi_{u},
$$

where $T_{\mathrm{a}}$ is the temperature anomaly $\left({ }^{\circ} \mathrm{C}\right)$. The indices have the same units as mentioned before. The multiple correlation coefficient is 0.84 which is statistically significant at the $0.01 \%$ level. The wind speed $V$ is dictated by westerly $(u)$ which is derived from the Icelandic low and Azores high (Chen and Hellström, 1999). Because of the unusually warm water in the eastern North Atlantic, the speed of the 
westerly wind has a positive effect on the temperature anomaly. The meridional wind $(v)$ can have either a positive or a negative influence on the temperature depending on the wind direction; northerly wind reduces temperature whereas southerly flows increase the temperature. However, due to the fact that $v$ is usually much less (an order of magnitude) than $u$ and $V$, its role in determining the temperature is relatively minor. It is found that the total vorticity is well represented by $\xi_{u}$. Thus, the statistical model indicates that the higher the vorticity, the higher the temperature. A positive value of vorticity means a lower pressure system whilst negative values indicate higher pressure. Therefore, this term reflects the positive or negative impacts of high or low-pressure systems, respectively. Due to the fact that $V$ and $\xi_{u}$ are often anticorrelated, i.e. when the wind is strong, the rotation of the flow is usually weak, their role in controlling the temperature is dependent on the situation and can thus be equally important.

Figure 6 displays the reconstructed temperature series based on Equation (7) using the indices together with the observed anomalies. As can be expected from the high correlation, the reconstruction is fairly satisfactory. It should be kept in mind that this model is only valid for January. In another study performed by Chen and Chen (1999), the relationship between the indices and seasonal temperature at 27 stations over Sweden has been examined. It is shown that the linkage between the indices and the temperature is generally strong, though a seasonal dependence is evident.

\section{CONCLUDING REMARKS}

The main purpose of this study is to derive a circulation climatology containing information about atmospheric circulation over Sweden. The classification system originally developed by Lamb is applied to obtain six circulation indices and a circulation catalogue with 27 circulation types on a monthly basis. This long-term climatology (1873-1995) is thought to be useful in regional climatological and environmental studies.

The frequencies of various circulation types for different periods are presented. Although 25 out of the possible total of 27 circulation appear, the frequency of most types is so small that only four types dominate. The most frequent types are identified as C, W, SW, and A. The cold season (Sep-Jan) is characterized by frequent directional flows, especially W and SW, whereas the warm period (Apr-Aug) has more frequent rotational flows dominated by $\mathrm{C}$. The period $\mathrm{Feb}-\mathrm{Apr}$ is considered to be transitional.

To demonstrate the usefulness of this climatology, the mean regional temperature for January in southwestern Sweden is studied with the help of the large scale circulation types and indices. It is shown

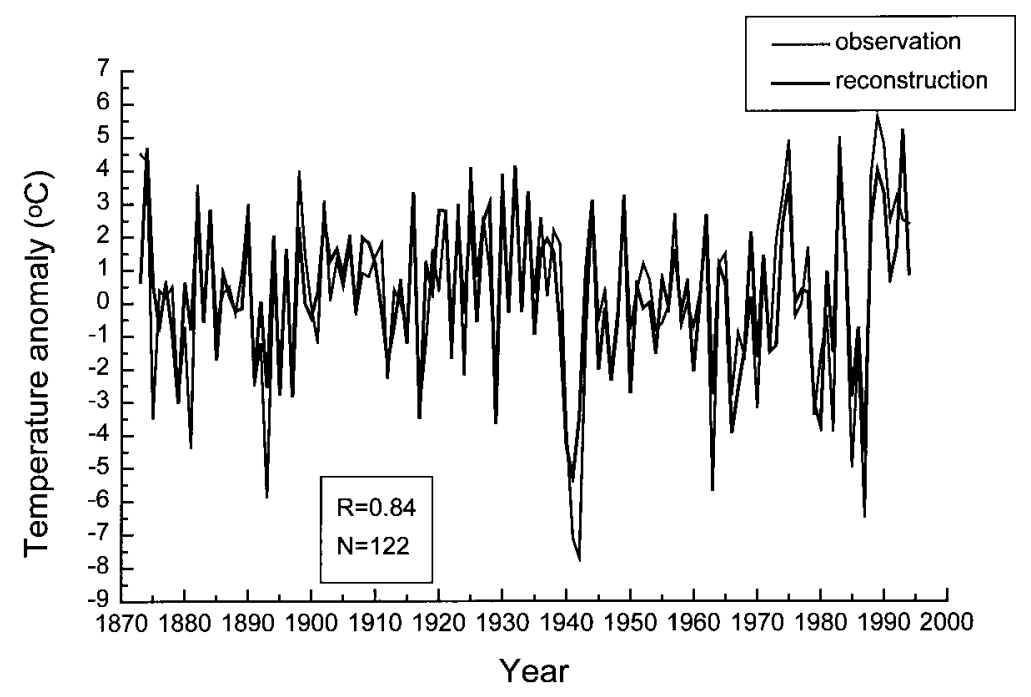

Figure 6. The observed and reconstructed temperature anomaly from 1861 to 1994 
that directional flows with a westerly component are often associated with positive temperature anomalies and the anticyclonic conditions favour negative anomalies. Extremely high temperatures, accompany the westerly or southwesterly flows which bring warmer air from the ocean. On the other hand, anticyclonic conditions cause subsidence and give rise to greater losses of radiative energy and weak exchange with the surrounding areas, leading to extremely low temperature. It is clear that the classification is helpful in interpreting the temperature anomalies.

Finally, the derived indices have been used to develop a statistical model linking temperature anomalies to circulation indices. It is established by stepwise multiple regression that only three indices are necessary to explain temperature variations adequately. In view of the fact that $70 \%$ of the total variance in the January temperature anomalies during 1887-1994 can be reproduced from only the pressure, it is concluded that the atmospheric circulation plays an important role in determining the winter climate in southwestern Sweden and the derived circulation climatology is a useful tool in regional climate research.

\section{ACKNOWLEDGEMENTS}

This is a part of the SWECLIM effort that is supported by MISTRA and SMHI. The author thanks Anders Moberg for providing the temperature data. Youmin Chen and Cecilia Hellström are acknowledged for assistance with plotting and calculation, respectively. This research is also partly supported by two NFR grants (G-AA/GU 11739-300 and G 11739-302).

\section{REFERENCES}

Bardossy A, Caspary HJ. 1990. Detection of climate change in Europe by analyzing European circulation patterns from 1881 to 1989. Theoretical and Applied Climatology 42: 155-167.

Barry RG. 1980. Synoptic and dynamic climatology. Process in Physical Geography 4: 88.

Barry RG, Kiladis G, Bradley RS. 1981. Synoptic climatology of the western United States in relation to climatic fluctuations during the twentieth century. Journal of Climate 1: 97-113.

Basnett TA, Parker DE. 1997. Development of the Global Mean Sea Level Pressure Data Set GMSLP2. Climatic Research Technical Note, No. 79. Hadley Centre, Meteorological Office, Bracknell, 16 pp. plus Appendices.

Briffa KR. 1995. The simulation of weather types in GCMs: A regional approach to control-run validation. In Analysis of Climate Variability, von Storch H, Navarra A (eds). Springer: Berlin; 122-138.

Chen D, Chen Y. 1999. Development and verification of a multiple regression downscaling model for monthly temperature in Sweden. In Preliminary Analysis and Statistical Downscaling of Monthly Temperature in Sweden. Report C16, Chen D, Hellström C, Chen Y (eds). Department of Earth Sciences, Göteborg University: Sweden; 41-55.

Chen D, Hellström C. 1999. The influence of the North Atlantic Oscillation on the regional temperature variability in Sweden: spatial and temporal variations. Tellus 51A(4): 505-516.

Davis RE, Kalkstein LS. 1990. Development of an automated spatial synoptic climatological classification. International Journal of Climatology 10: 769-794.

Jenkinson AF, Collison FP. 1977. An initial climatology of gales over the North Sea. Synoptic Climatology Branch Memorandum, No. 62. Meteorological Office, Bracknell.

Jones PD. 1987. The early twentieth century Arctic High_fact or fiction? Climate Dynamics 1: 63-75.

Jones PD, Kelly PM. 1982. Principal component analysis of the Lamb catalogue of daily weather types: Part 1, Annual frequencies. International Journal of Climatology 2: 147-157.

Jones PD, Hulme M, Briffa KR. 1993. A comparison of Lamb circulation types with an objective classification scheme. International Journal of Climatology 13: 655-663.

Key J, Crane RG. 1995. A comparison of synoptic classification schemes based on 'objective' procedures. Journal of Climatology 6: $375-388$

Kidson JW. 1994. Relationship of New Zealand daily and monthly weather patterns to synoptic weather types. International Journal of Climatology 14: 723-737.

Kilsby CG, Cowpertwait PSP, O'connell PE, Jones PD. 1998. Predicting rainfall statistics in England and Wales using atmospheric circulation variables. International Journal of Climatology 18: 523-539.

Kozuchowski KM. 1993. Variations of hemispheric zonal index since 1899 and its relationships with air temperature. International Journal of Climatology 13: 853-864.

Kozuchowski KM, Wibig J, Maheras P. 1992. Connections between air temperature and precipitation and the geopotential height of the $500 \mathrm{hPa}$ level in a meridional cross-section in Europe. International Journal of Climatology 12: 343-352.

Lamb HH. 1950. Types and spells of weather around the year in the British Isles. Quarterly Journal of the Royal Meteorological Society 76: 393-438.

Malmgren B, Winter A, Chen D. 1998. El Nino-Southern oscillation and North Atlantic oscillation control of Caribbean climate. Journal of Climate 11: 2713-2717.

Moberg A, Alexandersson H. 1997. Homogenization of Swedish temperature data. Part II: homogenized gridded air temperature compared with a subset of global gridded air temperature since 1861. International Journal of Climatology 17: 35-54. 
Perry AH, Barry RG. 1973. Recent temperature changes due to changes in the frequency and average temperature of weather types over the British Isles. Meteorological Magazine 102: 73-82.

Rossby CG. 1941. The scientific basis of modern meteorology in climate and man. In Yearbook of Agriculture. US Department of Agriculture: Washington DC; 599.

Schubert S. 1994. A weather generator based on the European 'Grosswetterlagen'. Climate Research 4: 191-202.

Trenberth KE, Paolino DA. 1980. The Northern Hemisphere sea-level pressure data set: trends, errors and discontinuities. Monthly Weather Review 104: 1354-1361.

Wallace JM, Gutzler DS. 1981. Teleconnections in the geopotential height field during the northern hemisphere winter. Monthly Weather Review 109: 784-812.

Yarnal B. 1984. The effect of weather map scale on the results of a synoptic climatology. Journal of Climatology 4: 481-493. 